\title{
Digital Divides in the Era of Widespread Internet Access: Migrant Youth Negotiating Hierarchies in Digital Culture
}

\author{
Koen Leurs
}

\begin{abstract}
In this chapter I analyse the digital practices of migrant youth as situated, power-laden, pleasurable and sometimes painful everyday experiences. I develop Walter Benjamin's theorisations of the nineteenth century "arcade" or commercial passageway (Benjamin W (1999) The Arcades project. Harvard University Press, Cambridge), together with Nirmal Puwar's understanding of how non-normative bodies become "space invaders" (Puwar N (2004) Space invaders: race, gender and bodies out of place. Berg, Oxford) upon entering certain domains, in order to conceptualise the digital spatial biases of online platforms and their subversions. The argument builds on survey, interview and ethnographic data gathered as part of the interdisciplinary research project Wired Up. Digital media as innovative socialisation practices for migrant youth run by Utrecht University. I argue firstly how offline societal power relations related to race and ethnicity, religion and gender relations travel online and create new digital divides that go beyond computer ownership and Internet access. Secondly, I argue how Internet platforms become spaces for the negotiation of power relations, digital belonging and greater cultural understanding in an increasingly multicultural world.
\end{abstract}

\section{Introduction}

In order to puncture recurring utopian and dystopian myths of technological determinism, I analyse the digital practices of Moroccan-Dutch youth to argue that contemporary digital media use among ethnic minorities is a situated, power-laden, pleasurable and sometimes painful everyday experience. Contemporary digital culture remains power-ridden, which urges us to reconsider the early notion of the digital divide; more attention is also needed for the empowerment users experience when negotiating digital inequalities and hierarchies. The argument builds on a quantitative survey $(n=1408)$, qualitative interviews $(n=43)$ and ethnographic data

\footnotetext{
K. Leurs $(\bowtie)$

Department of Media and Culture Studies / Institute for Cultural Enquiry (ICON), Utrecht University, Muntstraat 2a, Utrecht 3512 EV, Netherlands

e-mail: K.H.A.Leurs@uu.nl
} 
gathered in the context of the Utrecht University interdisciplinary research project Wired Up. Digital media as innovative socialisation practices for migrant youth.

As recently shown across the United States (Madden et al. 2013) and Europe (D'Haenens and Ogan 2013), with figures hovering around 90-95\% computer ownership is widespread and broadband Internet access has become the norm across different population segments. Young people of different backgrounds enjoy spending a large part of their leisure time using computers and other digital devices. The same holds true for the Netherlands. Wired $U p$ survey data reveal that $98.3 \%$ of Moroccan-Dutch girls and $96.9 \%$ of Moroccan-Dutch boys have a computer in their homes with Internet access. These numbers are comparable to the $97 \%$ of males and $96 \%$ of females among the general Dutch population that own computer hardware and have Internet access (CBS 2014a). However, beyond ownership and access, new situated digital divides need to be taken into account. Considering that social media users are promised new opportunities to contribute to digital culture, it shows that not everyone can participate equally. Excluding obstacles arise from default technological settings that are most often oriented towards (white, male, Western, middle-class) mainstream users and excluding norms emerge from the behaviour of the majority of users downplaying the input of minority users. However, how can we account for the time and energy minority users enjoy spending online? In other words, how can we consider digital inequalities and the empowering subversion of exclusionary practices?

Exploring these questions, the chapter provides a timely intervention in the debate on digital divides, as previous studies "largely fail to address the 'have-nots' as differentiated, possessing agency, or embedded in place, while simultaneously failing to address the crucial importance of intersecting relations of power" (Gilbert 2010, p. 1003). I focus both on how offline societal power relations intersecting race and ethnicity, religion and gender relations travel online and create new digital divides that go beyond computer ownership and Internet access. In addition, I aim to provide new insights into the ways in which Internet platforms are providing spaces for the negotiation of power relations, digital belonging and greater cultural understanding in an increasingly diverse world.

The argument is structured as follows. First, methodological considerations are given and the study is situated in the context of the Netherlands. Subsequently, the theoretical framework is presented by drawing an analogy between mid nineteenth century pedestrian passageways as described by Walter Benjamin and early twentyfirst century Internet applications like YouTube and Facebook to criticise uneven opportunities for peer-production. Subsequently, I transpose the concept of "space invaders" developed by Nirmal Puwar (2004) to digital platforms in order to scrutinise what happens when minority subjects enter spaces that have not been designed for them or that hold positions that they do not meet. The ways in which digital hierarchies are installed through the sociotechnical and algorithmic cultures of Google search's autosuggestions are charted and secondly, I elaborate how digital practices of mainstream users can serve to exclude ethnic minority subjects. The final empirical section presents three instances of how ethnic minority users can become "space invaders". 


\section{Methodological Considerations, in the Context of the Netherlands}

The fieldwork was conducted in the context of Wired $U p$, an interdisciplinary research programme (2008-2013) from Utrecht University (the Netherlands) which - in collaboration with Vanderbilt University in the USA - focused on how new digital media practices involving the Internet impact on the lives, identities, learning and socialisation of migrant youth. Bridging approaches from the humanities and social sciences, the primary aim of the project was to develop new conceptual tools and innovative methodological approaches to assess the socio-cultural specificities of digital practices among migrant youth from a comparative perspective (migrants versus native Dutch, youth with a Moroccan background in the Netherlands versus Mexican migrants in the USA, first and second generation migrants and girls versus boys). Combining quantitative and qualitative approaches, the empirical data gathering consisted of three phases.

Firstly, a large-scale online survey was developed, in which a total of 1408 young people were contacted through seven secondary schools in the Netherlands completed on computers during school hours. Out of the total number of 1408 respondents, 344 Moroccan-Dutch youth participated; this group consisted of 181 girls and 163 boys. On average they were 14.5 years $(\mathrm{SD}=1.7)$ old, and, when prompted, $98.5 \%$ described themselves as Muslim. In this chapter descriptive findings are used to present a general impression of digital media use frequencies, attachments to applications and online self-presentation practices. Secondly, I carried out ethnographically inspired in-depth interviews with a group of 43 Moroccan-Dutch individuals, 21 girls and 22 boys, between the ages of 12 and 18 years. With the aim of providing a broad context of identity deployments, a group of Moroccan-Dutch parents, website founders and artists were also interviewed. Through a virtual ethnography with a smaller group of informants texts were gathered from the four digital platforms the informants considered most important: discussion forums, instant messenger, social networking sites and video sharing platforms.

Moroccan-Dutch people are the second-largest minority group in the Netherlands, after those from a Turkish-Dutch background. Consisting of 374,996 people, those of Moroccan-Dutch descent make up some $2.2 \%$ of the total Dutch population of 16.7 million (CBS 2014b). Of this group, $47 \%$ migrated to the Netherlands from the 1960 s onwards as guest workers, while the other $53 \%$ were born in the Netherlands, after their parents had migrated. In the context of the Netherlands, young Moroccan-Dutch people receive a lot of attention in media reporting, governmental policy-making and scholarly research. They are systematically stigmatised and made hyper visible by right-wing journalists and politicians such as Geert Wilders and members of the Freedom Party (PVV), who describe them as anticitizens posing a threat to Dutch society. Prior academic research has predominantly focused on particular behaviour such as juvenile delinquency, radicalisation, mental health problems and early school leaving. These issues are undeniably 
important and significant, but they single out only a narrow slice of their experiences (Leurs et al. 2012). Things are going well for the majority of Moroccan-Dutch youth, but their realities remain largely invisible in contemporary debates. For example, more than $40 \%$ of second-generation youth follow higher education and it must be emphasised that this is a remarkable accomplishment; when considering a significant number of their parents were illiterate farmers who generally had received little schooling (De Valk and Crul 2008, p. 84).

My aim is to contribute to an emerging strand of scholarship that does not focus on excesses but that considers the everyday experiences of young migrants. In particular, digital media are taken as an entry point. Similar to young people engaging with the Internet elsewhere in the world, Moroccan-Dutch youth use digital media to circumscribe their individual identities and articulate group belongings. Analysing informants' practices will contribute to breaking down binary polarisations of social categories, by showing how Moroccan-Dutch youth negotiate between seemingly opposing gender, ethnic, diaspora and youth cultural identity positions via digital media. However, due to the dominant focus of previous scholarship on excessive, problematic and negative experiences, as outlined above, gaining access to members of the community has become difficult. In the qualitative fieldwork phases especially, I had to invest substantial energy to gain trust and overcome the suspicions of Moroccan-Dutch youth. I managed to circumvent this obstacle by emphasising my interest in the point of view of the young peoples themselves. It is a fact that these youth are often written and talked about while few people actually talk to these young people themselves. I therefore emphasised my interests in wanting to learn from the informant's personal experience about the role of the Internet in her/his life and her/his views on youth culture, discrimination, ethnicity, religion and gender issues across online and offline spaces. Continuously emphasising the views of the informants as a serious source of knowledge, I noticed how the rapport grew. Increasingly, they showed that they enjoyed being the centre of attention. Taken seriously as co-researchers of their everyday experiences, informants remained in touch for example, sending me links to videos, music and texts after the interviews.

\section{Spatial Approaches to the Digital Divide in Online Cultural Participation}

In this theoretical section, a brief and not all-encompassing overview is given of scholarship on the digital divide, before a plea is made to address hierarchies in contemporary participation in digital culture from the perspective of space. In particular, an analogy is drawn between Internet platforms and the writings of Walter Benjamin on nineteenth century arcades and Nirmal Puwar's notion of "space invaders" (2004) is transposed from the offline to the online world. 
Inequality in/of the Internet has first and foremost been analysed in terms of different digital divides. Scholarship on digital divides initially focused on making visible material divides across geographic scales and across markers of difference. An uneven geographical distribution in terms of ownership of hardware and access to the Internet was noted: the rich, overdeveloped parts of the world were found to be highly connected, while underdeveloped countries in the "Global South" were shown to be disconnected. Ownership and access was also unequally spread across different axes of differentiation: younger and/or white and/or upper class males were found to be more connected versus older and/or non-white and/or lower-class females. The term digital divide is thus ideologically loaded, particular in its proposal that once the gap is closed, a "computer-revolution" will take place, spreading democracy, promoting equality and potentially ending poverty (Murelli and OkotUma 2002). Emerging in the early 2000s, the second wave of scholarship on the digital divide shifted focus from access and ownership towards skills and literacies. The gaps between "the information haves" and the "information have-nots" were again purported as operating across geographical and personal markers of difference (Selwyn 2004). Policy makers and government institutions mobilised resources to provide the information have-nots with the skills for a more egalitarian distribution of knowledge. In sum, where previously most digital divide analyses "separate social inequalities from technical processes", today technology is essentialised as distinct from social processes and inequality is perceived as a dynamic that is independent from technology (Halford and Savage 2010, p. 937).

This chapter contributes to a new wave of situated scholarship on digital inequalities to move beyond technologically deterministic utopian and dystopian renderings of social media use. On the one hand, promising alternative ways of being and the collapse of difference, postmodernism and military-industrial neo-liberal progress came together in a Californian ideology that framed cyberspace as a disembodied, equalising, liberating, democratising and empowering world separated from the offline world. On the other side of the spectrum, techno-pessimists have made sweeping dystopian remarks in response to utopian appraisals of the Internet. Most famously, Jaron Lanier warns that digital technologies entail a loss of democracy, devalue individuality and deaden creativity (2010) and Evgeny Morozov argues Internet activism is a delusion that makes us unable to recognise technologies are used for purposes of propaganda, manipulation, censorship and surveillance (2011). These two perspectives do not, however, account for why migrant young people who for example encounter discrimination online still make heavy use of digital platforms.

As social media applications allow more people to have a presence online, scholars need to start acknowledging unevenness in people's contribution to digital culture while also paying attention to the feelings of agency and joy minority subjects experience in their negotiation of digital inequalities (Leurs 2015). Internet applications such as weblogs, social networking sites, video sharing platforms and online discussion forums signal the on-going shift from people being represented by the media to people representing themselves. Internet researchers have reached consensus in seeing the Internet as "an extension of life as it is, in all its dimensions, 
and all its modalities" (Castells 2001, p. 118). Online, digital spaces augment material, corporal and real offline lives, friendships, romance and socialisation. This is especially true for young people (Boyd 2014). However, little attention is paid to the differentiating power dynamics of the different locations where digital culture is expressed (Graham 2011). The lack of awareness of the spatial configurations of Internet applications is problematic because digital spaces are not neutral and/or innocent.

Building on the analogy of internet platforms as arcades and the notion of invasion of space I carve out a middle-ground position to account for how nonmainstream people in their everyday use are hailed and bound, but not fully determined, by medium-specific characteristics, commercial incentives and user norms. First I posit that Walter Benjamin's work on passages can be transposed to theorise social and symbolic meanings attributed to technological developments. In the mid nineteenth century, arcades or pedestrian passageways ("passages" in French) emerged in Brussels, Bologna and Paris among other places. Historically, the term arcade refers to a pedestrian passageway that links two streets. Unlike public space, this glass, iron or brick roofed passage is open at both ends and concentrates a row of commercial establishments (shops, cafés, restaurants) in a small space. In the words of Benjamin, arcades were "the most important architecture of the nineteenth century" $(1999$, p. 834). It can similarly be argued that internet platforms nowadays play an increasingly fundamental role in the daily lives of millions of people.

Benjamin recognised that these corridors carried an ambivalent meaning since as objects of history they simultaneously contained a "dream- and wish-image of the collective". He observed the dialectic tension between collective desires and exploitative "ruins". Indeed, Benjamin urged to ponder imaginations and to expose whether technology users were truly "emancipated" (Benjamin 1999, p. 115). As a "technical organ of the collective", innovations such as the arcades were imagined as a "new nature": "These images are wish images; in them the collective seeks both to overcome and to transfigure the immaturity of the social product and the inadequacies in the social order". "Caught in a dream", Benjamin added "the new, in order to shape itself visually, always connects its elements with those pertaining to a classless society". The "new nature" furthering utopian imaginings remains "concealed within machines". Instead of these imaginations, Benjamin argued for the figuration of "ambiguity". The role of the arcade is double-faced, as Benjamin illustrated: "during sudden rainshowers, the arcades are a place of refuge for the unprepared, to whom they offer a secure, if restricted, promenade - one from which the merchants also benefit" (Benjamin 1999, p. 31). Neither skepticism nor evangelism captured the dynamics of passages completely, and Benjamin aimed to capture them as a "constellation saturated of tensions" (Benjamin 1999, p. 475).

Although focused on the scrutiny of economic power relations in a striated, modernising society, the argument can be expanded to account for the ambiguous power relations which digital technologies sometimes conceal. Passages and insights on spatial power relations in a modern, democratising and urban crowded mass society allow us to draw parallels with contemporary forms of exclusion, distinction and 
contestation. Similarly, in their scrutiny of Internet culture, critical media and feminist theorists have argued for an ambiguous middle-ground position between the utopian dreams and dystopian nightmare perspectives that were dominant in writings on digital embodiment, identity and activism. Judy Wajcman, for example, unravels the constellation of gendered technologies from the perspective of "mutual shaping", "where neither gender nor technology is taken to be pre-existing, nor is the relationship between them immutable" (2007, p. 287). In particular I aim here to conceptually and empirically ground that the negotiating of hierarchies and inequalities online can be empowering.

Focusing on spatial relations in the built environment, Nirmal Puwar argued that British institutions such as parliament, the judiciary, civil service and academia are territories holding privileged positions that are historically "reserved". Recognising that including and excluding mechanisms operate around corporeal specificity, those who enter spaces of authoritative power are measured against the dominant template of "white male bodies of a specific habitus". Those who do not meet these normative expectations are positioned out of place; they become "space invaders" (2004, p. 141-144). Puwar developed the concept of space invaders to understand how ethnic minorities can feel out of place in institutionalised spaces. As they increasingly present themselves in spaces from which they were previously excluded through top-down governmental policies and bottom-up social climbing, she noted women and ethnic minorities may subvert the status quo but have to actively reposition themselves from within the spaces they invade. This re-positioning and decolonisation of dominant spaces relies on agency. Transposing the concept to account for digital spaces, I wonder how hierarchies are constructed and impact upon the digital practices of minority subjects.

Internet platforms increasingly promise users they can become active agents in charge of their own representations. My middle-ground perspective aims to acknowledge twenty-first century Internet platforms - analogous to nineteenth century arcades - as ambiguous constellations full of tensions and hierarchies but with room for subversion. Following Puwar, the question arises what happens when Moroccan-Dutch youth take up "privileged positions" that have not been "reserved" for them in digital space (2004, p. 144). When having to assert themselves against the grain, non-mainstream users become invaders of online territories. Below, I will first give examples of how digital spaces are constructed as prescriptive, normative spaces. Subsequently, I will explore how they can be subverted, invaded or transformed by the contributions of subaltern subjects by creating diversity in spaces that were previously defined as neutral and universal.

Across digital space, templates, norms and interface decisions reserve certain dominant consumer, national, gendered, ethnic and racial positions. These sociotechnical processes have uneven spatial effects, both online and offline. For example, Fig. 1 displays the dominant positions that the Google Netherlands search engine associated with "Marokkanen" (the Dutch word for Moroccans). The autocomplete search query suggestions that Google provides appear automatically upon typing Marokkanen in the search box. The auto-complete algorithm offered query suggestions in a drop-down list, predicting behaviour based on queries typed 


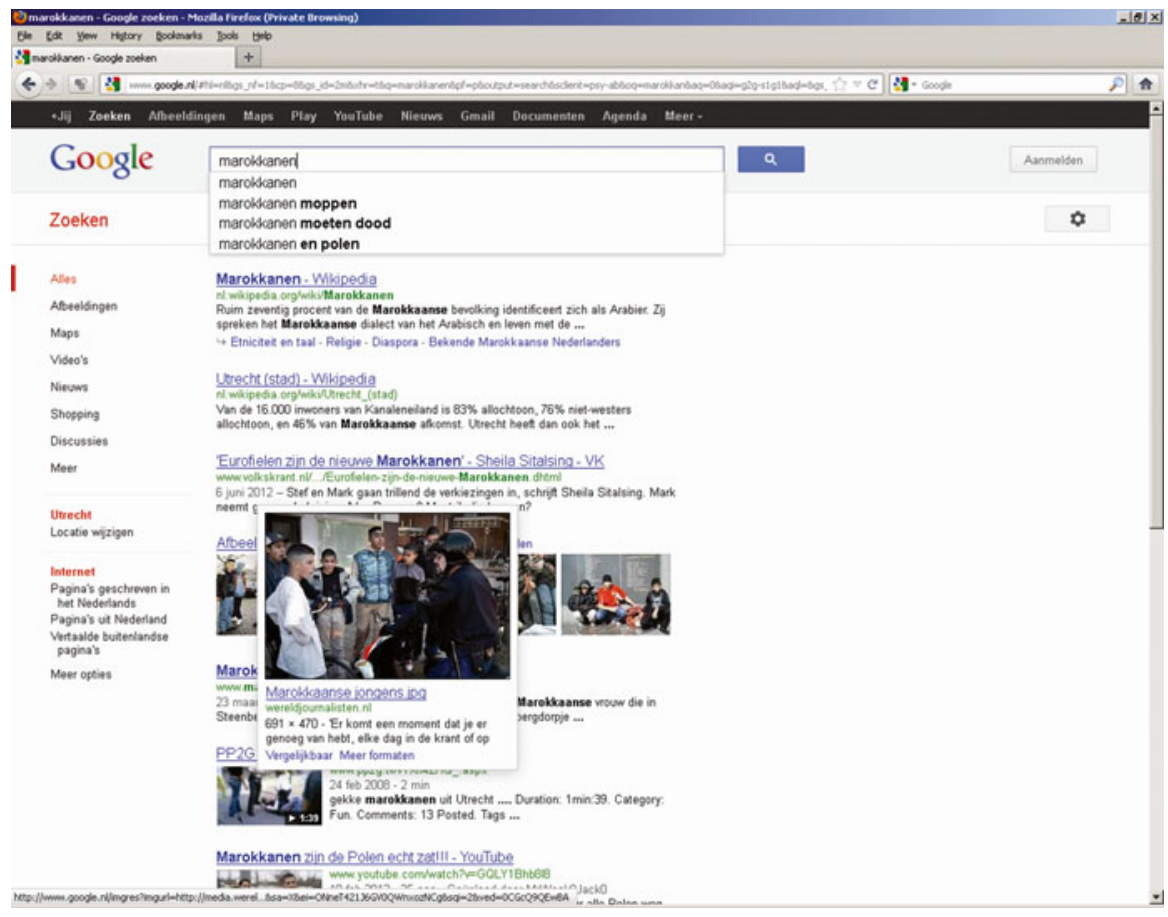

Fig. 1 The construction of exclusionary, normative digital spaces Google.nl search "Marokkanen" (June 28, 2012)

previously by Google users as well as generating items on the basis of traffic, page visits and recently crawled websites (Google 2012). ${ }^{1}$

Showing how algorithms may convey symbolic violence, the search query suggestions reveal some of the ways young Moroccan-Dutch people are allocated particular, narrow gendered and racialised positions in digital space. Reading from top to bottom they can be translated as follows: "Moroccan jokes", "Moroccans must die" and "Moroccans and Polish people". The suggestions for "Moroccan jokes" provide results of websites that host offensive anti-immigration, anti-Islam and racist jokes. The second suggestion points the Google user towards websites - mostly discussion forums - where white, right-wing extremist Dutch people discriminate against Moroccan-Dutch people. For example, the third result directs the user towards a forum posting on MeetHolland.com where the following comments are published in relation to Moroccan-Dutch youth: "Those rotten bastards must die!!!!!!!!! Dirty, cowardly, disgusting, stinking cancer goats" (Wilders 2005). The third suggestion equates Moroccan-Dutch people with a more recent group of guest

\footnotetext{
${ }^{1}$ The search was carried out in a Mozilla Firefox browser, using the 'Private Browsing' settings, without being logged in to a Google account and without having searched for the topic earlier. The results do thus not present my earlier search behaviour or that of my contacts.
} 
workers, Polish people. Simultaneously, without having pressed the search button, Google lists search results, including Google Image Search findings. The four images are all stereotypical representations of aggressive masculine street culture showing Moroccan-Dutch youth as dangerous loiterers and the inclusion of a policeman emphasises Moroccan-Dutch boys as troublemakers.

The auto-complete algorithm (which is partly based on search-term popularity among previous search engine users) exemplifies received ideas that emphasise particular associations and stereotypes of Moroccan-Dutch people - particularly those voiced by populist, anti-Islamic politician Geert Wilders and his "Freedom Party", PVV - rather than others. Spearheaded by Wilders and a sensationalist press, young people of Moroccan migrant descent are often framed as a problem. MoroccanDutch boys are dismissed as "strangers" to Western society, possibly dangerous "Islamic fundamentalists", "street-terrorists" or "thieves" while headscarf-wearing girls are constructed as either "un-emancipated and backward" or "oppressed by Muslim culture". The example given in Fig. 1 is not a temporary glitch since a similar search query on 29 May 2012 included the following suggestions: "Moroccans must die", "Moroccans must exit the country".

In the context of the United States, danah boyd similarly described that when searching for the name "Mohammed" for example, Google auto-complete provides suggestions related to Islamic extremism and terrorism. She defines this process as a form of "guilt through algorithmic association", as the search suggestions for Mohammed exemplify how people can be "algorithmically associated with practices, organisations, and concepts that paint them in a problematic light" (Boyd 2011). The auto-complete example reminds us that digital space is not neutral but power-ridden. Similar to how nineteenth century arcades were imagined, a platform on the "Internet hails its audiences", in a way that is similar to how non-digital environments are intended for particular groups of people (Nakamura and Lovink 2005, p. 65).

The examples discussed above attest to how these ideologies may be perpetuated through commercial algorithms, but participants of digital culture also constitute them themselves. During my fieldwork, many informants shared their frustrations and anger of the ignorance, discrimination and hate-speech they encountered in their engagement with Internet platforms. For instance, 16-year-old Naoul's statements were harsh reminders of the politics of difference on YouTube. ${ }^{2}$ Naoul said that the comment sections for videos pertaining to Morocco sometimes fill up with verbal abuse and hostility: "when you watch a video on YouTube, they [referring to white, ethnic majority Dutch people] shout cunt-Moroccans and this and that about Moroccans". Exclusionary majority user norms were also apparent in Dutch video game culture, where Islam was equated with terrorism. A fan of the game Counter Strike, 15-year-old Oussema shared that he had bad experiences after he disclosed his ethnic and religious background: "When saying I am Moroccan, I am a Muslim, I get called a terrorist". Eighteen-year-old Safae told me after her friend who covers

\footnotetext{
${ }^{2}$ The names of interviewees used in this chapter are pseudonyms, mostly suggested by the informants themselves.
} 
her hair uploaded a picture on the Dutch social networking site Hyves, somebody sent her a message typing "a headscarf is out-dated, and it's something of the past". Thus, digital spaces are not mere mute, neutral and external backdrops of identity formation, but distinct expressive cultures filled with ideologies, hierarchies and politics.

\section{Space Invader Tactics}

Although digital spaces are interspersed with politics and exclusionary practices, during the interviews informants shared the fact that they enjoy spending a lot of their time online and that they have many tactics to keep their use enjoyable. I explore three of those space invader tactics below. Revealing the ambiguous constellation of tensions Internet platforms present to Moroccan-Dutch youth, I will present three examples of their negotiation of power relations here: racial passing, perpetuating common teenager gender stereotypes and appropriating a digital space of their own.

\subsection{Racial Passing}

The first tactic to be discussed is racial passing. During our interview, 15-year-old Ryan explains that he is accepted as a gamer because, as he argued, he does "not look like a Moroccan", in the sense that he was seen as "very different from what normal Moroccan youth in [his] school do". He "mostly only plays games on the computer" and he felt gaming is more white "Dutch culture" as it is mostly white "Dutch kids who play games". He was accepted as he backgrounded his Moroccan affiliations during in-game interaction using voice-chat programs like Skype or Teamspeak: "when I talk I do not appear to be Moroccan". On his Hyves profile page he also subverted the dominant image of Moroccan-Dutch youth: "when someone sees me there, they say I do not look like a Moroccan, but obviously I am one, but I do not let it show". Masking his Moroccan identity, Ryan passed as an ethnic majority Dutch boy. Homi Bhabha, who recognised processes of passing as "mimicry", described the ambivalence of racial passing. Mimicry offers camouflage and can become a site of resistance and transgression. The minority subject achieves "partial presence" by passing for someone one they are not and "becoming a subject of a difference that is almost the same, but not quite" (Bhabha 1994, p. 122-133). Ryan did so by strategically employing dominant cultural repertoires and making less visible the ways he deviates from majority norms while emphasising resemblances. Choosing the pseudonym Ryan during the interview can also be seen as an act of passing, as the informant did not opt for a Moroccan or Dutch but an English first name. Ryan's act of passing offered self-protection but also reflected his desire to be accepted by the majority group. Nakamura noted that "racial impersonation" 
is a form of passing that "reveals a great deal about how people 'do' race online". However, she rightly argued that passing does keep the foundations of dominant exclusionary, white national identities intact (Nakamura 2002, xvi, 37). Although such digital forms of racial passing offers us insight into the empowerment that may be felt through the temporal dismissal of excluding norms, the foundations of cultural difference and the othering of non-mainstream users remains intact.

\subsection{Perpetuating Teenager Gender Stereotypes}

Taking and uploading photographs of the self, "selfies" have been recognised as offering innovative tools to "see and shape ourselves" (Walker Rettberg 2014). This section scrutinises to what extent the gendered self-presentation of Moroccan-Dutch youth can be an empowering tactic for migrant youth to forge alliances with mainstream users. In the Wired $U p$ survey respondents were asked how they would show themselves in their profile pictures in order to be liked by their friends. With this question we aimed at learning more about the norms of selfies and displaying pictures among young people. Answers given to the question allow for reflecting on impression-management, expectations of appropriate self-presentations and ideal beauty-standards among Moroccan-Dutch youth.

The survey findings show that nearly half of the Moroccan-Dutch girls and boys in the survey sample reported they would like to present themselves as "normal" (Fig. 2). In addition to the label "normal", boys and girls chose specific labels to describe their aspired self-presentation. Commonly chosen labels indicate that participating girls specifically desired to look "beautiful", "sweet" or "fashionable/ trendy" and "social" and to a lesser extent "attractive/sexy", "intelligent" and "tough". Boys wanted to come across as "sporty", "tough", "beautiful", "attractive/ sexy", and to a lesser extent "sweet", "rich", "intelligent", "hard working" and "computer savvy". These findings reveal how Moroccan-Dutch youth would ideally represent themselves. Striving to meet expectations of what is accepted as normal and standard in selfies and profile-page culture seems an important ideal. Meeting the normal standard is combined with the perpetuation of dichotomous gender ideals. Girls' ideals are being beautiful and sweet, while boys aim for a sporty image and toughness. Being expected to showcase certain attributes, these ideals reveal self-regulatory values young people negotiate with. Each of the chosen labels covers a distinct configuration of femininity and masculinity, stereotypical ideals that are not unproblematic.

During my interviews, informants described the stereotypically gendered practice of profile photo selection. Oussema described that most boys show themselves as follows: "look at how pretty I am, look at how nice my eyes are as a ray of light shines in it" or they pose in their pictures with "pumped up chests" and aimed to go for a "look at how tough I am, look at how muscled I am" impression, while girls "lean over", showed their bodily curves and "blow a kiss to the camera". Fourteenyear-old Ziham said boys "put up tough photos, where they put up their middle-fingers 


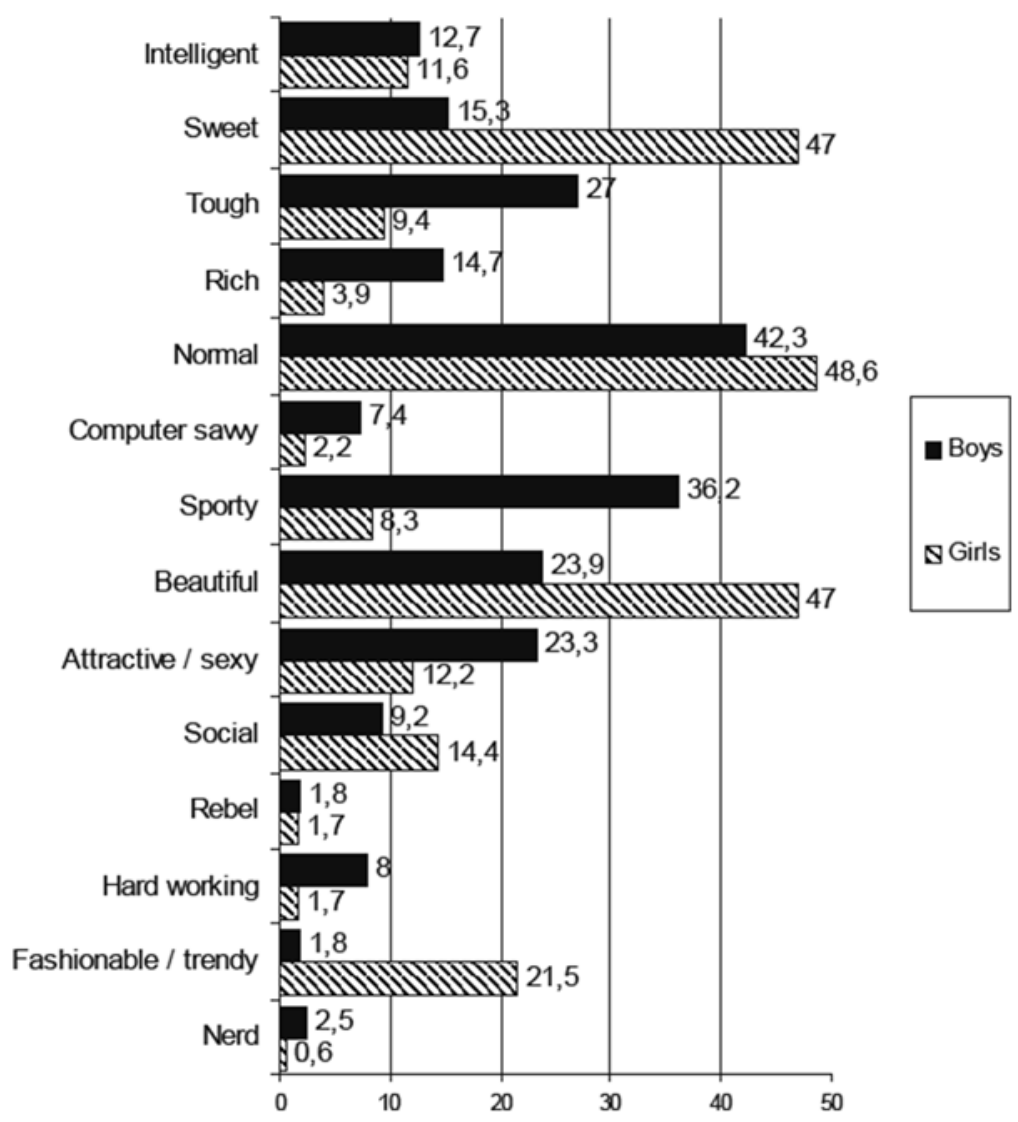

Fig. 2 Moroccan-Dutch youth self-reporting their selfie ideals (Graph shows percentages, $n=344$ )

and so on", she added that among her friends "girls don't do that. They just show themselves wearing tight clothes or so, with untied hair". According to 16-year-old Bibi, in some photos "girls show their boobs almost popping out of their bras". Fourteen-year-old Ayoub noted "girls put lots of make-up on" or showed pictures "when they have just come from the shower". Although individual informants often nuanced their own positioning, the majority of the informants gave a highly stereotypically gendered description of photograph ideals. Andra Siibak in Estonia (2009) and Michele Strano in the United States (2008) have found similar self-presentation strategies, for instance girls aim to display ideals of female beauty on their online social networking profile pages. These findings suggest that shared teenage norms of gender go beyond ethnic groups. Striving to meet expectations of what is accepted as normal and standard in profile-page culture seems an important ideal. Meeting these standards is one example of seeking sameness, stressing commonalities and aiming for acceptance among fellow white teenagers. As Moroccan-Dutch youth choose to adapt their profile picture to meet widely used gendered norms, they 
highlight commonalities and seek sameness instead of emphasising differences. In addition, taking charge of their own selfies for self-representation purposes, these minority subjects navigate the continuum between empowerment and objectification. In the case of uploading selfies to one's profile page, a female informant's internalisation of gendered stereotypes might indicate she seized the opportunity "to be in charge of her to-be-looked-at-ness" (Smelik 2009, p. 185). This opportunity, however, becomes increasingly difficult as the celebrated visual ideals of youth, fitness and beauty are becoming more and more unrealistic and unattainable, especially in the present era of widespread digital manipulation.

\subsection{Appropriating a Corner of One's Own}

It is a sort of support. As a process of feeding [your emotions], by sort of reacting to each other. You'll have everyone who backs you up. It's like everyone is on the same side. You kind of become more sure of yourself. You just know, yes look we are not the only ones who think this way and so on. Thus you can express your opinion and just put everything up and you hear that others are similar to you. - Ilham, 13 years old.

During our interview, Ilham eloquently described the emotional support she received from being able to secure speaking power on the online discussion forum Marokko.nl. Message boards, also known as Internet forums, are digital spaces where users can engage in conversations by publicly posting messages in response to each other. Ilham noted that her self-confidence grew from being able to publish her opinions and connect with other like-minded people. She had the agency to publish her own opinions, in contrast with being positioned in certain ways by others. Seizing the opportunity to speak for herself and hearing others appreciate her voice, Ilham self-consciously claimed membership within a group of people of her choice. By doing so, she felt heard, she got confirmation that she was not the only one out there who felt a certain way. Through such discussions, similarity can actively be foregrounded and an alternative supportive community can be formed.

The Wired Up survey findings indicate a distinct preference for engaging with discussion boards among ethnic minorities in the Netherlands: Moroccan-Dutch youth reported visiting online discussion boards more than ethnic majority Dutch youth. One in every five Moroccan-Dutch youth reported visiting online discussion boards for at least 4 days per week, while only one in every ten ethnic majority Dutch respondents reported doing so. Moroccan-Dutch respondents also reported being more attached to visiting online discussion boards than ethnic majority Dutch youth are. Additionally, they would miss Internet forum discussions if they were no longer able to participate in them, more so than Dutch majority youth reported. These findings resonate with earlier studies that suggest that message boards are especially popular among minority subjects (Byrne 2008).

During the interviews I learned that forums like Marokko.nl, Chaima.nl and Maroc.nl are felt as a safe space to connect with fellow Moroccan-Dutch youth. As 
15-year-old SouSou states: "Marokko.nl is a website where especially Moroccans come so to say". As Naoul, a 16-year-old girl notes: "Marokko.nl is a community", "it is your own circle, with all those Moroccan things" that are discussed and "the people there are like you, that's nice". Being a "corner of one's own", these sites are frequented to create a space where Moroccan-Dutch youth can become the majority. Boundary markers such as Moroccan images and symbols that include photos taken in Morocco, Arabic typing, visual references to Islam like a minaret and the Quran as well as photos of veiled women are circulated. Furthermore, in the discussion, users can reframe dominant stereotypical views circulating in news media. Sixteenyear-old Nevra finds that "different stories" are shared on Internet forums, where "there is often negative talk about Moroccan youth [in the newsmedia], I find that youth there can say what they want, showing it is not all bad". However, such moments of empowerment are not uncontested. When ethnic minorities find the opportunity to voice themselves, their contributions are often quickly pigeonholed or marginalised. Journalists and politicians seem to criticise and dismiss Internet forums such as Marokko.nl. Public news media link discussion sites frequented by Moroccan-Dutch individuals to extremism and radicalism, with newspaper items such as: Cut-and-paste-Islam: how young Muslims in the Netherlands compose their radical worldview (Oostveen 2004, my translation). Additionally, these sites are dismissed as the underbelly of the unknown, as encapsulating grimy spaces disconnected from mainstream society: "Gettos on the web. On the Internet, every group creates its own truth" (Hulsman 2005, my translation). As the site has no control over who subscribes and posts, anti-immigrant and Islamophobic users are also present on the site. It is estimated that $20 \%$ of Marokko.nl visitors come from the Dutch right-wing blog Geenstijl.nl or are supporters of the right-wing PVV. Internet scholar Albert Benschop added that those visitors sometimes setup a profile like Mohammed21 and discredit the site with extremist statements, after which they can complain about the site (Knijff 2009). Nonetheless, it remains significant that the informants perceive the forums they frequent as safe zones where they can articulate alternative ways of being, although their acts simultaneously remain subject to tight scrutiny and control.

\subsection{Hybridisation}

Another commonly observed tactic is the hybridisation of affiliations. Inzaf, for instance, logged in to MSN Messenger using the display name "El Hoceima is the bom, that's the place where I come from so just tell everyone that's the city number $O N E$ ". Explaining its significance during our interview, she shared: El Hoceima "means a lot to me because that is the town in Morocco where I am from, I was not born there but my father was and I want to show that I am proud of it". She added, "it rhymes in English" and it is "nicer to say it in English than in Dutch". Through hybridisation, different loyalties can be combined. She signalled transnational affiliations with the city of El Hoceima in Morocco but she used the vocabulary of 
English-language global hip-hop youth culture as well as Internetspeak. She used the nickname to emphasise her individuality, but also to connect with her peers. Consider also the display name of a young male informant consisting of both Latin and Arabic characters, "Mф محمد BadBoy". In the latter netspeak, Mø is combined with Arabic alphabet characters to write the name Mohammed. The name also integrates a connection to mainstream global hip-hop culture by referencing BadBoy, the record label set up by Sean P. Diddy Combs. Similarly, circulating on groups like "Imazighen" on social networking sites such as the Dutch Hyves and Facebook, informants posted statements such as "Amazighen!! 4-Evaah" and "Amazigh. My Pride. My Life", referring to the Amazigh, or Berber people, the Moroccan ethnic minority group with which most Moroccan-Dutch migrant youth identify. Or take the example of the profile image circulating on various MoroccanDutch SNS group pages that showed Bart Simpson, the young and rebellious main character in the animated television series The Simpsons, dressed up in clothes with the Moroccan red and green starred national flag. Adored by young people across the world for his disrespect for adult authority, he was depicted wearing a hoody sweater and speaking into the microphone, again referencing urban and street youth culture. Such acts of hybridisation reflect active intercultural encounters. Similarly, Ayhan Kaya has argued that young Turkish-Germans in Berlin used hip-hop youth culture to mingle in the mainstream cultural field. These young people tapped into universal symbols such as rap, cool looks, graffiti and dance to mark a social, cultural and political space in the urban landscape. In their appropriation and recirculation of hip-hop youth culture, migrant youth may combine their "aesthetics of diaspora" and "global transcultural capital" (2002, p. 45). Hip-hop as such is a creative repository that enables ethnic minority youth to appropriate its elements, connect with their co-ethnics and peers, and insert themselves into global youth culture.

\section{Conclusions}

What remains insufficiently addressed are the very real and material ways in which space constitutes a site and a medium for the enactment of cultural power - Raka Shome (2003, p. 40)

This chapter sought to move beyond understanding digital divides as a matter of ownership, access or literacy, by arguing participation in Internet platforms is characterised by forms of spatial power relations that are not yet sufficiently understood (Gilbert 2010; Halford and Savage 2010; Leurs 2015). The question then arises how subjects on the wrong side of the template and peer-produced digital divide invade prescriptive spaces, transforming them from within but also creating alternative platforms for communication and belonging.

To answer this question, I have extended Walter Benjamin 's writing on nineteenth century arcades and Nirmal Puwar's notion of "space invaders" by coupling their writings with empirical data on the digital practices of Moroccan-Dutch youth. 
The optics of the arcade and space invaders can be developed further to empirically trace and theorise digital spatial biases and their subversion but also to intervene in dominant techno-determinist utopian and dystopian thinking about digital media potentialities. The empirical examples showcased that Internet platforms and their terrains are hierarchical territories and that they are uneven geographies marked by symbols and discursive borders. As the Google search auto-complete suggestions and informants' experiences of discrimination and exclusion I have discussed exemplify, mainstream (young, white, male and middle-class bodies) participating in mainstream digital spaces produce and occupy certain templates and reserved positions. When having to assert themselves against the grain, non-mainstream users such as ethnic minorities become space invaders of digital locations. Through racial passing, perpetuating common teenage gender selfie stereotypes and hybridisation, migrant youth show their offline and online "mixed embeddedness" by mobilising empowering opportunities to establish "bridging" and "bonding" relationships with fellow ethnic majority youth (Codagnone and Kluzer 2011; Peeters and D'Haenens 2005). Digital spaces are thus best considered as part of the everyday, real-life, uneven power relations, where offline and online spheres infuse each other with meaning.

\section{References}

Benjamin, W. (1999). The arcades project. Cambridge: Harvard University Press.

Bhabha, H. (1994). The location of culture. New York: Routledge.

Boyd, D. (2014). It's complicated: The social lives of networked teens. New Haven: Yale University Press.

Boyd, D. (2011). Guilt through algorithmic association. Apophenia. http://www.zephoria.org/ thoughts/archives/2011/09/12/guilt-through-algorithmic-association.html. Accessed 13 Jan 2016.

Byrne, D. N. (2008). The future of (the) 'race': Identity, discourse, and the rise of computermediated public spheres. In A. Everett (Ed.), Learning race and ethnicity: Youth and digital media (pp. 15-38). Cambridge, MA: MIT Press.

Castells, M. (2001). The internet galaxy. Oxford: Blackwell.

CBS. (2014a). ICT gebruik van personen naar persoonskenmerken. http://statline.cbs.nl/StatWeb/ publication/?DM=SLNL\&PA=71098ned $\& \mathrm{D} 1=33-133 \& \mathrm{D} 2=0-3 \& \mathrm{D} 3=\mathrm{a} \& \mathrm{HDR}=\mathrm{G} 1 \& \mathrm{STB}=\mathrm{T}$, G2\&VW=T. Accessed 13 Jan 2016.

CBS. (2014b, January 1). Population; sex, age, origin and generation. http://statline.cbs.nl/ Statweb/publication/?DM=SLEN\&PA=37325ENG\&D1=0\&D2=0\&D3=0\&D4=0\&D5=139\& D6=1\&LA=EN\&VW=T. Accessed 13 Jan 2016.

Codagnone, C., \& Kluzer, S. (2011). ICT for the social and economic integration of migrants into Europe. European Commission, Institute for Prospective Technological Studies. http://ftp.jrc. es/EURdoc/JRC63183.pdf. Accessed 13 Jan 2016.

D'Haenens, L., \& Ogan, C. (2013). Internet-using children and digital inequality: A comparison between majority and minority Europeans. Communications-The European Journal of Communication Research, 38(1), 41-60.

De Valk, H., \& Crul, M. (2008). Education. In M. Crul \& L. Heering (Eds.), The position of the Turkish and Moroccan second generation in Amsterdam and Rotterdam (pp. 63-85). Amsterdam: Amsterdam University Press. 
Gilbert, M. (2010). Theorizing digital and urban inequalities. Information, Communication \& Society, 13(7), 1000-1018.

Google. (2012). Autocomplete. Inside search. http://support.google.com/websearch/bin/answer. py?hl = en\&answer $=106230$. Accessed 11 Sept 2013.

Graham, M. (2011). Time machines and virtual portals: The spatialities of the digital divide. Progress in Development Studies, 11(3), 211-227.

Halford, S., \& Savage, M. (2010). Reconceptualizing digital social inequality. Information, Communication \& Society, 13(7), 937-955.

Hulsman, B. (2005, January 8). Getto's op het web. Op internet heeft elke groep zijn eigen waarheid (p. 33). NRC Handelsblad.

Kaya, A. (2002). Aesthetics of diaspora: Contemporary minstrels in Turkish Berlin. Journal of Ethnic and Migration Studies, 28(1), 43-62.

Knijff, C. (2009, November 6). Marokko.nl: Nuttige kijk op de onderbuik. Volkskrant.

Lanier, J. (2010). You are not a gadget: A manifesto. London: Penguin Group.

Leurs, K. (2015). Digital passages: Migrant youth 2.0. Diaspora, gender and youth cultural intersections. Amsterdam: Amsterdam University Press.

Leurs, K., Midden, E., \& Ponzanesi, S. (2012). Digital multiculturalism in the Netherlands: Religious, ethnic, and gender positioning by Moroccan-Dutch youth. Religion and Gender, 2(1), 150-175. http://www.religionandgender.org/index.php/rg/article/download/36/pdf_1. Accessed 13 Jan 2016.

Madden, A., Lenhart, A., Duggan, M., Cortesi, S., \& Gasser, U. (2013). Teens and technology 2013. Pew Research Centre. http://www.pewinternet.org/files/old-media//Files/Reports/2013/ PIP_TeensandTechnology2013.pdf. Accessed 13 Jan 2016.

Morozov, E. (2011). The net delusion: The dark site of internet freedom. New York: Public Affairs.

Murelli, E., \& Okot-Uma, R. W. O. (2002). Breaking the digital divide: Implications for developing countries. London: Commonwealth Secretariat.

Nakamura, L. (2002). Cybertypes: Race, ethnicity and identity on the Internet. New York: Routledge.

Nakamura, L., \& Lovink, G. (2005). Talking race and cyberspace: An interview with Lisa Nakamura. Frontiers: A Journal of Women Studies, 26(1), 60-65.

Oostveen, M. (2004, November 27). De knip- en plak-islam; Hoe jonge moslims in Nederland hun radicale wereldbeeld samenstellen (p. 38). NRC Handelsblad. http://vorige.nrc.nl//dossiers/ moslimterreur/moslims_in_nederland/article1629224.ece/De_knip-_en_plak-islam. Accessed 13 Jan 2016.

Peeters, A., \& D'Haenens, L. (2005). Bridging or bonding? Relationships between integration and media use among ethnic minorities in the Netherlands. Communications-The European Journal of Communication Research, 30(2), 201-231.

Puwar, N. (2004). Space invaders: Race, gender and bodies out of place. Oxford: Berg.

Selwyn, N. (2004). Reconsidering political and popular understandings of the digital divide. New Media \& Society, 6, 341-362.

Shome, R. (2003). Space matters: The power and practice of space. Communication Theory, 13(1), $39-56$.

Siibak, A. (2009). Constructing the self through the photo selection. Journal of Psychosocial Research on Cyberspace, 3(1). http://www.cyberpsychology.eu/view.php?cisloclanku= 2009061501. Accessed 13 Jan 2016.

Smelik, A. (2009). Lara Croft, Kill Bill, and the battle for theory in feminist film studies. In R. Buikema \& I. van der Tuin (Eds.), Doing gender in media, art and culture (pp. 178-192). Oxford: Routledge.

Strano, M. M. (2008). User descriptions and interpretations of self-presentation through Facebook profile images. Cyberpsychology: Journal of Psychosocial Research on Cyberspace, 2(2). http://cyberpsychology.eu/view.php?cisloclanku=2008110402\&article=5. Accessed 13 Jan 2016. 
Wajcman, J. (2007). From women and technology to gendered technoscience. Information, Communication \& Society, 10(3), 287-298.

Walker Rettberg, J. (2014). Seeing ourselves through technology: How we use selfies blogs and wearable devices to see and shape ourselves. New York: Palgrave.

Wilders, P. (2005, October 18). En wederom van die laffe kankermarokkanen. Forum posting, Meetholland. https://web.archive.org/web/20120125074934/http://old.meetholland.com/message/708037.aspx. Accessed 13 Jan 2016. 